\title{
BY THE OLD GODS AND THE NEW: THE EFFECT OF THE CONGRUENCE AND INCONGRUENCE OF FOREIGN LANGUAGE CLASSROOM ANXIETY AND ENJOYMENT ON SELF-PERCEIVED PROFICIENCY
}

Authors:

1. Elouise Botes (contact person) University of Luxembourg 2 Avenue de 1'Université 4365

Esch-sur-Alzette

Luxembourg elouise.botes@uni.lu

2. Prof. Jean-Marc Dewaele (Birkbeck College, University of London)

3. Prof. Samuel Greiff (University of Luxembourg) 


\begin{abstract}
The negative emotion of Foreign Language Classroom Anxiety (FLCA) and the positive emotion of Foreign Language Enjoyment (FLE) have both been linked to foreign language (FL) learners' Self-Perceived Proficiency (SPP). In linear correlational studies, SPP has been found to be negatively affected by FLCA and positively affected by FLE. However, linear correlational research methods are limited in the extent to which they can depict these interrelations. In this study, we examined how different levels of FLCA and FLE influenced SPP in concert in a sample of $n=1039$ FL learners by utilising polynomial regression with response surface analysis. The response model generated visually depicted a complex SPP pattern as a result of differing levels of FLCA and FLE. This three-dimensional model provides considerable insight into the interaction of positive and negative emotions above and beyond what could be derived from 'classical' methods of correlation and linear regression.
\end{abstract}

Keywords: Foreign Language Classroom Anxiety; Foreign Language Enjoyment; SelfPerceived Proficiency; polynomial regression; response surface analysis 


\section{BY THE OLD GODS AND THE NEW: THE EFFECT OF THE CONGRUENCE AND INCONGRUENCE OF FOREIGN LANGUAGE CLASSROOM ANXIETY AND ENJOYMENT ON SELF-PERCEIVED PROFICIENCY}

The role of emotions in foreign language (FL) learning has recently received considerable research attention (Dewaele \& Proietti Ergün, 2020; Dewaele, Chen et al., 2019). The two variables at the forefront of emotion research in applied linguistics are the negative emotion of Foreign Language Classroom Anxiety (FLCA) and the positive emotion of Foreign Language Enjoyment (FLE; Dewaele \& MacIntyre, 2014, 2016). Numerous previous studies have examined the individual associations of FLCA and FLE, respectively, with the proficiency of language learners (see Dewaele \& Dewaele, 2017; Li, Dewaele, \& Jiang, 2019; Wei, Gao, \& Wang, 2019), and some have also examined the interaction between FLCA and FLE (Jiang \& Dewaele, 2019).

Previous studies have all utilised linear methods such as group averages, correlations, and linear regressions to examine these associations. However, these 'classical' methods, though methodologically sound, are limited in that they simplify the relations between variables to such an extent that it might not do justice to the complexities of the realities of the foreign language classroom (Gkonou, 2017). A nonlinear method that allows users to establish associations that go beyond mere linear trends is therefore needed to accurately reflect the full range of emotions experienced by FL learners. Such a method can be found in polynomial regression with response surface analysis. Specifically, polynomial regression with response surface analysis is a powerful methodology that can be used to examine the nonlinear effects of two psychological constructs on a third variable (Edwards, 1994; Humberg, Nestler, \& Back, 2019). The plotting of a congruence effect between the two independent variables in a three-dimensional space offers a 
unique opportunity to examine the interaction of complex psychological variables beyond what linear regression models can do (Shanock et al., 2010). Of note, polynomial regression has often been used in the fields of Personality Psychology and Occupational Psychology (Dörendahl, Niepel, \& Greiff, 2020; Edwards, 2007), but to our knowledge, it has yet to be used in the field of applied linguistics. Therefore, the following study has two main aims, namely: (a) to examine how FLCA and FLE in concert influence Self-Perceived Proficiency (SPP) through a threedimensional response surface model and (b) to introduce the method of polynomial regression with response surface analysis to the field of applied linguistics by examining the aforementioned research question.

As the authors of this study, we previously examined the correlational relationships between FLCA, FLE, and proficiency (Botes et al, 2020a). Specifically, we utilised an existing data set comprising $n=1039$ adult FL learners to examine the interaction between multilingualism and Self-Perceived Proficiency on FLCA and FLE (Botes et al, 2020a). In this previously published study, FLCA was found to be negatively correlated with SPP $(r=-.340, p<$ $.001)$, whereas FLE was positively correlated with $\operatorname{SPP}(r=.245, p<.001)$. In addition, other studies have confirmed an existing linear relationship between emotion variables and perceived proficiency in the FL classroom (see Li, Jiang, \& Dewaele, 2018; Zhang, Dai, \& Wang, 2020). Furthermore, Li et al. (2019) found an interaction between FLE and FLCA that predicted the perceived achievement of FL learners. The conclusions of our own and other studies have therefore been that, to optimise the SPP of the FL learner, FLE should be maximised and FLCA should be minimised. However, this simple maxim might not reflect the reality of the FL classroom, where learners can experience equally high or low levels of FLCA and FLE with nonadditive effects on the outcome variable (e.g., SPP). 
Quantitative studies based on correlations, including our own, have found a prevailing moderate negative correlation between FLCA and FLE (see Botes et al., 2020a; Dewaele \& MacIntyre, 2014, 2016; Khajavy, MacIntyre, \& Barabadi, 2018), yet qualitative and quantitative research studies are rife with reports of students experiencing high levels of FLCA and FLE simultaneously (see Dewaele, MacIntyre, Boudreau, \& Dewaele, 2016; Dewaele, Özdemir, et al., 2019). The varying combinations of FLCA and FLE that FL students can experience might therefore be overly simplified when only correlational results are examined.

In addition, the range of combinations of FLCA and FLE that can be present in FL learners are not necessarily reflected in hypotheses that propose linear relationships with a third variable. Numerous mixed-methods research studies have presented cases of language learners who display high levels of language anxiety in conjunction with high levels of proficiency/achievement (see Dewaele \& Alfawzan, 2018; Gkonou, 2017; MacIntyre, 1995), despite the prevailing moderate negative correlation between language anxiety and academic achievement ( $r=-.39$; cf. the recent meta-analysis of 59 studies by Botes et al., 2020b). Furthermore, FL learners have also displayed low levels of enjoyment in combination with high levels of perceived proficiency (Li et al., 2019). Therefore, many combinations are possible with regard to FL learners' emotions, with learners displaying equally high, equally low, or opposing levels of FLCA and FLE.

Greater nuance is therefore needed in examining the interplay of FLCA and FLE and its effects on third variables. Such nuance may be achieved by examining the variables by applying polynomial regression and response surface analysis, as the response surface model will provide a three-dimensional depiction of how the level of agreement between FLCA and FLE affects the SPP of the FL learner. More specifically, this three-dimensional model will depict the SPP of FL 
learners as influenced by different possible combinations of FLCA and FLE. Specifically, the model will depict the resultant SPP when FLCA and FLE are experienced in equally high or equally low amounts (congruence) or at complete opposite levels (incongruence). In this study, we therefore re-examined the data set used by Author (2020) in an attempt to understand the nuances that exist in the emotions of FL learners and moved beyond the classical linear interpretation of the data.

In addition, as far as we are aware, no attempt has been made in the literature to investigate individual difference variables in FL learning by applying polynomial regression with response surface analysis. Therefore, this study will attempt to provide a brief introduction to polynomial regression with response surface analysis and provide information about the methodological steps involved in the hope of inspiring additional research that might employ this method. Please note that other fields of social science have readily employed polynomial regression with response surface analysis, and the interested reader will find methodological introductions to the topic (see Edwards, 1994; Edwards \& Parry, 1993; Schönbrodt \& Humberg, 2018; Shanock et al., 2010).

\section{LITERATURE REVIEW}

\section{Emotions in Language Learning}

FLCA remains the most commonly studied emotion in FL learning (Dewaele \& MacIntyre, 2014) and was originally defined as "a distinct complex of self-perceptions, beliefs, feelings, and behaviours related to classroom language learning, arising from a uniqueness in the language learning process" (Horwitz, Horwitz, \& Cope, 1986, p. 128). FLCA has since become a cornerstone of individual differences in FL learning research. Three decades of continual research 
on the topic have led to a complex understanding in the prevailing literature of the debilitating effects of language anxiety during the process of FL learning (Horwitz, 2010; 2017; MacIntyre, 2017).

More recently, the emergence of positive psychology principles in applied linguistics research (Dewaele, Chen, et al., 2019; MacIntyre, Gregersen, \& Mercer, 2019) has led to the development of Foreign Language Enjoyment (FLE). Positive psychology emphasises the enabling power of positive characteristics and behaviours in creating positive outcomes, breaking away from the traditional overt interest in negative diagnostics prevalent in psychological research (Seligman \& Csikszentmihalyi, 2014). In this framework, FLCA can be seen as an embodiment of traditional, diagnostic-based emotion research, with extensive research attention provided in the past 30-odd years to examining the antecedents, malleability, and consequences of FLCA. In opposition, FLE encompasses the concept of the broadening ability of positive emotions (Fredrickson, 2001).

In recent years, a great deal of research attention has been given to the relationship between the established construct of FLCA and the newly introduced construct of FLE. In the seminal study that introduced FLE to the research lexicon, Dewaele and MacIntyre (2014) questioned whether positive and negative emotions in FL learning resembled the two-faced Roman god Janus in that FLCA and FLE presented two sides of a single continuum. However, the study concluded that due to a moderate negative correlation $(r=-.36, p<.001)$, FLCA and FLE can be viewed as largely independent but related variables (Dewaele \& MacIntyre, 2014). Indeed, subsequent research has confirmed that FLCA and FLE manifest differently not only in terms of their bivariate relation but also in terms of their antecedents (Dewaele \& Dewaele, 2017; Jiang \& Dewaele, 2019), inherent design, and factor structure (Li et al., 2018). 
FLCA and FLE have been established as related variables within a largely shared nomological network, as both emotion constructs have been found to interact with established variables in FL learning motivation research. For instance, FLCA has been associated with numerous affective, personality, and cognitive variables in the decades-long research into the nature of language anxiety (see MacIntyre, 2017). By contrast, the nomological network of FLE is as yet underdeveloped.

Essentially, both FLCA and FLE have been linked to real and perceived competence in the target language through correlations and linear regressions. Patterns of significant, moderately high, negative correlations between FLCA and the outcome variables of academic achievement, actual proficiency, and self-perceived proficiency have been reported in the literature (see Botes et al., 2020a; MacIntyre, 2017; Teimouri et al., 2019). Additionally, FLE has been found to be significantly positively moderately correlated with academic achievement, actual proficiency, and self-perceived proficiency (Mierzwa, 2018; Wei et al., 2019). Furthermore, linear regression studies have found that FLCA negatively predicts actual and self-perceived proficiency (Dewaele \& Ip, 2013; Ghorbandordinejad \& Ahmadabad, 2016; Lu \& Liu, 2011), whereas FLE positively predicts the actual and perceived proficiency of FL learners (Li et al., 2019; Zhang et al., 2020).

Only a few studies have examined the interplay between FLCA and FLE in contrast to vast amounts of research detailing the individual correlations and regressions. We could find only a single study that explicitly examined the effect of the interaction between FLCA and FLE on real and perceived achievement in the FL classroom. Li et al. (2019) reported a statistically significant effect of the interaction between FLCA and FLE on real proficiency $\left(R^{2}=.115, p<.001\right)$ and SPP $\left(R^{2}=.293, p<.001\right)$. Aside from the statistically significant interaction effect, it should be noted 
that individually, FLCA had a considerably larger effect on SPP $(\beta=-0.426, p<.001)$ than FLE $\operatorname{did}(\beta=0.201, p<.001)$.

The hypothesised relationships between FLCA and FLE as independent variables and SPP as a dependent variable have therefore been previously established as individual linear relationships. However, the possible dynamic combinations of FLCA and FLE experienced by the FL learner that cannot be depicted by linear methods also ought to be taken into account. In fact, research regarding idiodynamic changes in emotions in FL learning have provided insights into the dynamic interplay between FLCA and FLE on a moment-to-moment basis during FL classroom activities (see Boudreau et al., 2018; De Ruiter, Shirvan, \& Talebzadeh, 2019; Shirvan \& Talebzadeh, 2018). FLCA and FLE have been found to have both converging and diverging trajectories on a moment-to-moment basis (Boudreau et al., 2018), thus indicating a complexity in the interplay of emotions experienced by the FL learner on a state level that is not necessarily reflected in previous research with linear methods. The interplay between FLCA and FLE can also be examined on a situation-specific level—with SPP as the outcome variable - through the use of polynomial regression with response surface analysis.

\section{Polynomial Regression and Response Surface Models}

As previously noted, the first aim of the current paper was to examine the interplay between FLCA and FLE in relation to SPP via a nonlinear method that can be applied to achieve greater nuance in our understanding of the roles emotions play in the FL classroom. The second aim was to introduce the specific nonlinear method, namely, polynomial regression with response surface modelling, to the field of applied linguistics in particular. Polynomial regression and response surface analysis can be used to investigate "the extent to which combinations of two predictor variables relate to an outcome variable, particularly when the discrepancy between the two 
variables is a central consideration" (Shanock et al., 2010, p. 543). First introduced as a means for examining person-environment fit in organisational settings (Edwards, 2007; Edwards \& Cable, 2009), response surface analysis has since become popular in personality and educational psychology settings (see Chopik \& Motyl, 2016; Ilmarinen, Lönnqvist, \& Paunonen, 2016; Milatz, Lüftenegger, \& Schober, 2015). This methodology might hold great promise in providing further insights into the relationships between applied linguistics variables that cannot be gained through direct linear methods.

On a more specific level, polynomial regression is concerned with examining how the congruence between two predictor variables affects the standing on a third latent variable, where congruence refers to the "fit, similarity, or agreement between two constructs" (Edwards, 2009, p. 34). In this study, the fit between FLCA and FLE is therefore proposed to affect the outcome variable of SPP. However, a key factor of polynomial regression that sets it apart from the use of linear methods is the importance given to both congruence and incongruence in the relation between the two predictor variables. Congruence between the predictor variables [++; --] is seen as quantitatively distinct from incongruence $[+-;-+]$, and the relationship between the congruence of the predictor variables and the outcome variable is not the direct opposite of the relationship between the incongruence of the predictor variables and the outcome variable (Edwards, 1994). In the present study, we therefore expected that different combinations of FLCA and FLE scores would result in a nonlinear relationship with SPP, both when FLCA and FLE were roughly at equal levels (equally high or equally low levels of enjoyment and anxiety) and when they were at exact opposite levels (e.g., high anxiety and low enjoyment).

On a formal level, polynomial regression examines two predictor variables separately and jointly in that the calculated model rests on the centred predictors as well as on the interaction of 
the joint predictors with a third outcome variable (Edwards, 2007). Thus, the outcome variable (in this study: SPP) is regressed on each of the predictor variables (in this study: FLCA and FLE), on the interaction between the two predictor variables, and on the squared values of each of the predictors. The quadratic polynomial regression equation is calculated as follows:

$$
\begin{aligned}
& Z=b_{0}+b_{1} X+b_{2} Y+b_{3} X^{2}+b_{4} X Y+b_{5} Y^{2}+e \\
& \text { Where: } \\
& \qquad \begin{array}{l}
Z=\text { Outcome variable (SPP) } \\
X=\text { First predictor (FLCA) } \\
Y=\text { Second predictor (FLE) } \\
Y^{2} \text { and } X^{2}=\text { Quadratic terms for the predictors } \\
X Y=\text { Interaction between the predictors } \\
b_{1} \text { to } b_{5}=\text { Estimated coefficients }
\end{array}
\end{aligned}
$$

$$
\begin{array}{ll}
a_{1}=b_{1}+b_{2} & \begin{array}{l}
\text { Slope along the line of congruence, where FLCA and FLE are in } \\
\text { perfect agreement (Lines A to D in Figure 1) }
\end{array} \\
a_{2}=b_{3}+b_{4}+b_{5} & \begin{array}{l}
\text { Curvature along the line of congruence (Lines A to D in Figure 1) } \\
a_{3}=b_{1}-b_{2}
\end{array} \\
a_{4}=b_{3}-b_{4}+b_{5} & \begin{array}{l}
\text { Slope along the line of incongruence, where FLCA and FLE are at } \\
\text { opposite levels (Lines B to C in Figure 1) }
\end{array} \\
\text { Curvature along the line of incongruence (Lines B to C in Figure }
\end{array}
$$

The above equation can be depicted in a three-dimensional space using response surface analysis for ease of interpretation. The surface estimates of the two predictor variables are mapped onto this three-dimensional space, and the lines of congruence and incongruence are of interest (see 
Figure 1) (Edwards, 1994). Most notably, the characteristics of interest on the response surface are the slopes and curves of the lines of congruence and incongruence, which are depicted by calculating the four surface test parameters:

The slopes and curves calculated above describe the nonlinear relationships between the variables when they are statistically significant (see Shanock et al., 2010). Test parameters $a_{2}$ and $a_{4}$ additionally provide information about the direction of the curvature, such that a positive and statistically significant outcome yields a convex curve, and in turn, a negative and statistically significant outcome indicates a concave curve. The response surface may also present a pattern where both a convex and concave line is present on either the line of congruence and incongruence and is aptly termed a 'saddle' curve (Edwards, 2007). In terms of the specific variables at play in this study, a concave model implies that greater SPP was observed in instances where FLCA and FLE were at either extreme (very high or very low). In turn, a convex curvature implies that a higher SPP was observed when both FLCA and FLE were experienced at moderate levels (at Point E in Figure 1). 


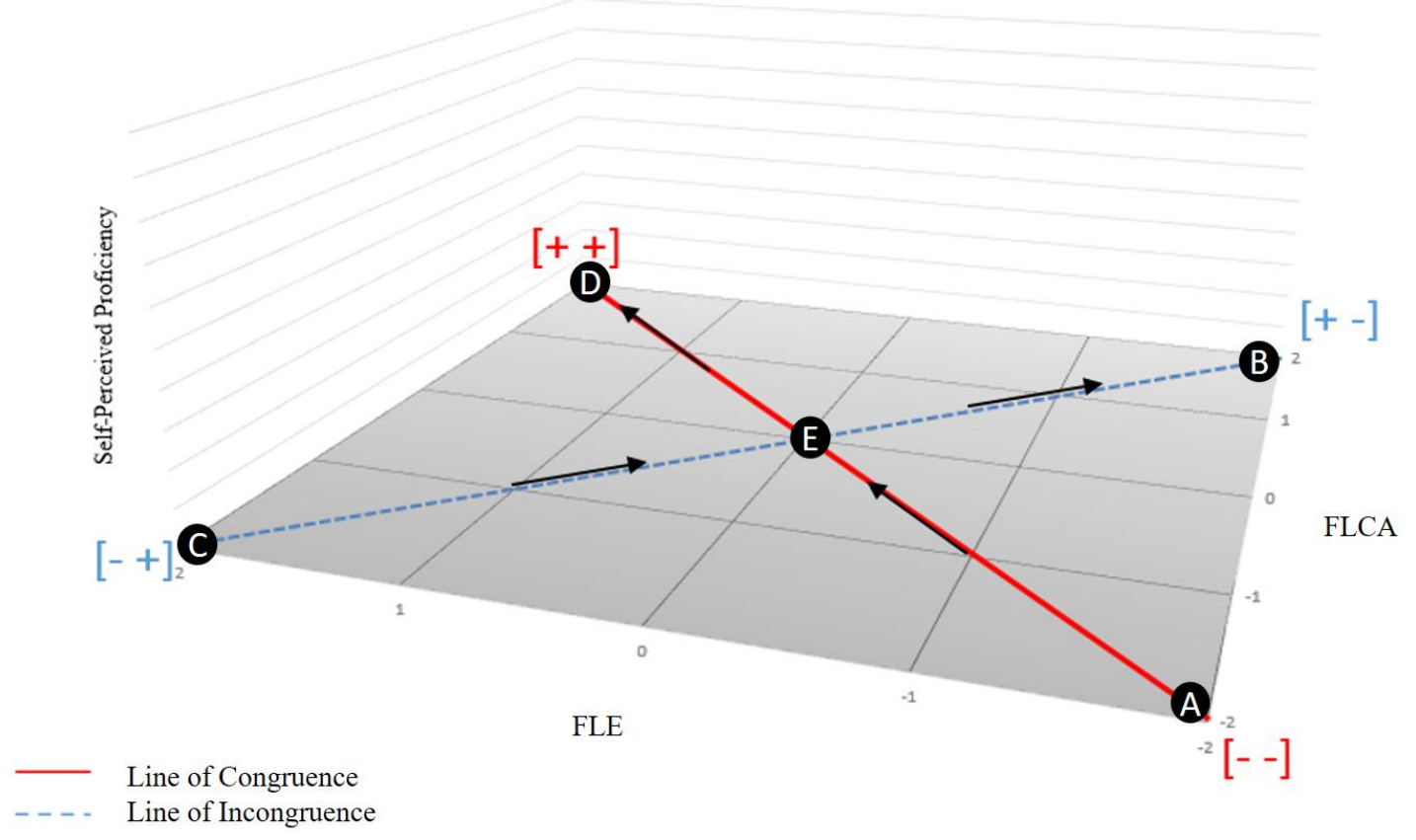

Figure 1. Three-dimensional space of the response surface pattern.

It should also be noted that the use of polynomial regression with response surface analysis is not without criticism. The methodology relies on the assumption that the variables are measured without error, as measurement error is not taken into account (Edwards, 2009). In addition, there is a risk of extrapolating results from the sample to the general population by applying oversimplistic interpretations. Therefore, results garnered from polynomial regression and response surface analysis should be cross-validated (Edwards, 1994). The most often cited criticism against the use of the methodology lies in its apparent complexity, as it may lead to misinterpretations and misconceptions (Cohen et al., 2010). However, the introduction of numerous Microsoft Excel macros (see Edwards, 2007; Shanock et al., 2010) as well as RStudio packages such as RSA (Schönbrodt \& Humberg, 2018) have simplified the analysis and interpretation of congruence results in recent years. 
Therefore, with the current article, we hope to spark interest in the use of the methodology in the field of motivational studies in language learning. Therefore, we explored the ranges of emotions that language learners can have in the language classroom as well as how the fit and misfit between their emotions influence SPP as the outcome variable. The use of this methodology will expand the understanding of the role that emotions play in the FL classroom. Specifically, we give due attention to cases that are generally not depicted in linear methods (e.g., when FL learners experience equally high levels of FLCA and FLE).

\section{METHOD}

\section{Participants}

The sample consisted of $n=1039$ FL learners who completed an online questionnaire in $2012^{1}$. The average age of the sample was 24.04 years $(S D=8.01)$, with $71.66 \%$ of the sample

\footnotetext{
${ }^{1}$ As mentioned above, the data set was previously used to examine the linear and correlational relationships between FLCA, FLE, and SPP (Botes et al., 2020a). In our previous study (Botes et al., 2020a), we examined the interaction effect of multilingualism and SPP as predictors on the emotions of FLCA and FLE as criteria as direct consequence of previous research findings indicating significant differences in FLCA and FLE across levels of SPP and multilingualism (Dewaele, 2016; Thompson \& Khajawa, 2016). In this study, we deploy the method of polynomial regression with response surface analysis to re-examine this same dataset in order to determine whether FLCA and FLE in congruence predict SPP. There are, therefore, differences in the directionality assumed across our previous study (multilingualism with SPP $\rightarrow$ FLCA and FLE; Botes et al., 2020a) and our current study (FLCA and FLE $\rightarrow$ SPP). Neither study should be taken as a definitive stance on the directionality of the relations between the variables in the nomological network. Instead, we assume a circular relationship between the emotion variables and SPP, where, for example, low FLCA can predict low SPP but, in turn, low SPP can predict anxiety. This 'spiral' prediction is not uncommon in studies of emotion, where anxiety has been theorised to have a spiralling effect on the performance of musicians (Spahn et al., 2010), drivers (Fairclough, Tattersall, \& Houston, 2006), sales agents (Mughal, Walsh, \& Wilding, 1996), mathematics learners (Jameson, 2014), and language learners (Saito \& Samimy, 2006). Ideally, future experimental research would examine the negative spiral between SPP and FLCA as well as the positive spiral between SPP and FLE that we put forth in theory, however such a study is beyond the scope of this paper.
} 
identifying as female. The data were gathered via snowball sampling and were originally used in the study that introduced FLE (Dewaele \& MacIntyre, 2014).

\section{Materials}

Self-Perceived Proficiency. A single item was used to measure SPP. Participants were asked to indicate their level of mastery/proficiency regarding the FL they were learning at the time on a scale ranging from 1 (Beginner) to 5 (Advanced).

Foreign Language Classroom Anxiety Scale $(\alpha=.89)$. We used an eight-item measure that is a shortened version of the original 33-item scale developed by Horwitz et al., (1986). Items are scored on a 5-point Likert scale ranging from 1 (strongly disagree) to 5 (strongly agree).

Short-Form Foreign Language Enjoyment Scale $(\alpha=.82)$. We used a nine-item short-form scale (Botes, Dewaele, \& Greiff, 2020b) that was adapted from the original 21-item Foreign Language Enjoyment Scale by Dewaele and MacIntyre (2014). The items were rated on a 5-point Likert scale ranging from 1 (strongly disagree) to 5 (strongly agree).

\section{Data Analysis}

Data were analysed using the Statistical Package for the Social Sciences (SPSS 25), the Microsoft Excel macro for response surface analysis developed by Edwards (2007), and the RSA package in R (Schönbrodt \& Humberg, 2018). Descriptive statistics were calculated for all three variables. All assumptions for running response surface analysis were examined, as specified by Humberg et al. (2019). 
Polynomial regression and response surface analysis were used to examine the effect of the possible congruence and incongruence between FLE and FLCA on SPP through the following detailed steps:

1. As recommended by Edwards (1994), the predictors of FLE and FLCA were centred on the midpoint of their respective scales. Both FLE and FLCA were measured on a 5-point Likert scale ranging from 1 (strongly disagree) to 5 (strongly agree). As such, the midpoint of both scales was 3; therefore, 3 was subtracted from the average score of FLE and FLCA for each participant in the sample. By doing so, two new variables were calculated: A centred FLE $\left(b_{1}\right)$ and a centred FLCA $\left(b_{2}\right)$.

2. Three additional variables required for the quadratic polynomial regression equation were calculated: The square of the centred FLE scores $\left(b_{3}\right)$, the product of the centred FLE scores multiplied by the centred FLCA scores $\left(b_{4}\right)$, and the square of the centred FLCA scores $\left(b_{5}\right)$.

3. The outcome variable (i.e., SPP) was regressed on each of the five calculated variables $\left(b_{1}\right.$ $\left.-b_{5}\right)$ in order to derive each of the surface test values $\left(a_{1}-a_{4}\right)$. As previously described, the surface test values represent the slope and curvature of the response surface along the lines of congruence and incongruence.

4. The unstandardized betas and standard errors of the regression coefficients calculated in Step 3 were entered into the Edwards (2007) Excel macro, which, in turn, generated a response surface model for each of the dependent variables. Figures were generated in the RSA package in R (Schönbrodt \& Humberg, 2018).

\section{RESULTS}

Descriptive Statistics 
The descriptive statistics for all three variables can be found in Table 1 .

Table 1

Descriptive Statistics

\begin{tabular}{lllll}
\hline & $M$ & $S D$ & Max & Min \\
\hline FLCA & 2.70 & 0.83 & 5 & 1 \\
FLE & 3.84 & 0.57 & 5 & 1.11 \\
SPP & 3.73 & 1.12 & 5 & 1 \\
\hline
\end{tabular}

Preanalysis Requirement Checks

The data requirements were confirmed as specified by Humberg et al. (2019): (a) the distribution of discrepant predictor pairs in the data (i.e., FL learners whose FLCA is higher, lower, and equal to their FLE), (b) the multicollinearity between FLCA and FLE, (c) the reliability of the measurements, and (d) the statistical power of the data.

A suitable amount of discrepancy was found in the data set with regard to the pairs of predictors so that a polynomial regression analysis could be justified (see Table 2). In order to examine the discrepancies between the independent variables, the scores were standardized for both FLCA and FLE. The differences between the two scores were coded to identify participants whose standardised score on FLCA was half a standard deviation above or below FLE (Shanock et al., 2010). Thus, discrepancy pairs were coded as follows: FLCA higher than FLE, FLCA equal to FLE, and FLCA lower than FLE within half a standard deviation.

Table 2

Discrepancy Pairs of Independent Variables within Half a Standard Deviation 


\begin{tabular}{lll}
\hline & $\mathrm{n}$ & $\%$ \\
\hline FLCA higher than FLE & 371 & 35.71 \\
FLCA = FLE & 261 & 25.12 \\
FLCA lower than FLE & 407 & 39.17 \\
\hline
\end{tabular}

As we found in our previous study, statistically significant correlations were observed between all variables (Botes et al., 2020a; see Table 3). FLCA had a statistically significant moderate negative correlation with the outcome variable of SPP $(r=-.35, p<.001)$. In turn, FLE had a moderate positive correlation with SPP $(r=.37, p<.001)$. The moderate negative correlation between FLCA and FLE indicated low multicollinearity between the two predictor variables $(r=-.26, p<.001)$. Furthermore, a variance inflation factor of 1.074 was found between FLCA and FLE, thus meeting the collinearity requirements for further analysis (Humberg et al. 2019).

Table 3

Correlation Matrix

\begin{tabular}{llll}
\hline & 1. & 2. & 3. \\
\hline 1. FLCA & - & $-.26^{* *}$ & $-.35^{* *}$ \\
2. FLE & & - & $.37^{* *}$ \\
3. SPP & & & - \\
\hline$* * p<.01$. & & &
\end{tabular}

The last two requirements specified by Humberg et al. (2019), namely, the reliability of the measures and the power of the data, were also met. The FLCAS and S-FLES, which were used to measure FLCA and FLE, respectively, both indicated an acceptable level of internal reliability 
with $\alpha=.89$ and $\alpha=.82$. Unfortunately, a reliability analysis could not be conducted on SPP as a single item was used to measure the dependent variable. Lastly, the sample size of $n=1039$ was more than sufficient to examine the hypothesis in question (Humberg et al., 2019). As all requirements were met, the polynomial regression with response surface analysis proceeded.

\section{Polynomial Regression and Response Surface Model}

The relations of FLCA and FLE with SPP were examined via polynomial regression and response surface analysis. The variables required for the quadratic polynomial regression were calculated as described in the data analysis $\left(b_{1}-b_{5}\right)$, where $b_{1}-b_{5}$ were the estimated coefficients of FLCA and FLE. The outcome variable of SPP was regressed onto each of the calculated variables $\left(b_{1}-b_{5}\right)$, with the surface test values $\left(a_{1}-a_{4}\right)$ calculated from the regression model results (Edwards, 2002).

Table 4

Polynomial Regression Results of FLCA and FLE on SPP

\begin{tabular}{llllll}
\hline Variable & Description & Est. & SE & $\beta$ & $p$ \\
\hline $\mathrm{b}_{1}$ & FLCA centred & -.388 & .039 & -.385 & $<.001 * * *$ \\
$\mathrm{~b}_{2}$ & FLE centred & -.02 & .063 & -.013 & .751 \\
$\mathrm{~b}_{3}$ & FLCA squared & .026 & .024 & .027 & .279 \\
$\mathrm{~b}_{4}$ & FLCA x FLE & .088 & .04 & .093 & $.027 *$ \\
$\mathrm{~b}_{5}$ & FLE squared & .118 & .04 & .129 & $.004 * *$ \\
$\mathrm{a}_{1}$ & $\left(\mathrm{~b}_{1}+\mathrm{b}_{2}\right)$ & -.41 & .09 & & $<.001^{* * *}$ \\
$\mathrm{a}_{2}$ & $\left(\mathrm{~b}_{3}+\mathrm{b}_{4}+\mathrm{b}_{5}\right)$ & .23 & .07 & & $.002 * *$
\end{tabular}




\begin{tabular}{lllll}
$\mathrm{a}_{3}$ & $\left(\mathrm{~b}_{1}-\mathrm{b}_{2}\right)$ & -.37 & .06 & $<.001 * * *$ \\
$\mathrm{a}_{4}$ & $\left(\mathrm{~b}_{3}-\mathrm{b}_{4}+\mathrm{b}_{5}\right)$ & .06 & .08 & .467 \\
\hline${ }^{*} p<.05 .{ }^{* *} p<.01 . * * * p<.001$. & & &
\end{tabular}

The overall polynomial regression model of SPP as the outcome variable was statistically significant, $F(5)=52.47, p<.001$. As the regression model was significant, the interpretation of the response surface model could proceed (see the two angles of the model in Figures 2 and 3).

The line of congruence in the response surface model was interpreted via the slope and curvature of the line ( $a_{1}$ and $a_{2}$ ). The slope of the line of congruence was significantly negative ( $a_{1}$ $=-.41, p<.001$ ), and therefore, SPP decreased as FLCA and FLE increased. In turn, the curvature of the line of congruence was significantly positive $\left(a_{2}=.23, p<.01\right)$. The significant $a_{2}$ variable indicated a nonlinear relationship on the line of congruence, which resulted in a convex curvature (see the first angle of the response surface model in Figure 2). Therefore, more extreme levels of FLCA and FLE led to a greater SPP. Where very high FLCA and FLE were present, a moderate level of SPP was expected. In addition, where very low FLCA and FLE were present, an even greater level of SPP was found.

The line of incongruence, in turn, resulted in a significant negative slope $\left(a_{3}=-.37, p<\right.$ .001). Therefore, a very low SPP was present at the point where low FLE and high FLCA occurred (see Point B in the second angle of the model in Figure 3). As FLE increased and FLCA decreased along the line of incongruence, a resultant rise in SPP occurred. This result was not unexpected, as it duplicated the linear findings of our previous studies, with low FLCA and high FLE resulting in high SPP (Botes et al., 2020a). In addition, the curvature of the line of incongruence was found to be nonsignificant (at: $p=.467$ ). Therefore, no significant curvature was found on the line of 
incongruence, with a steady linear increase in SPP present between Points B and C where FLE rose and FLCA fell.

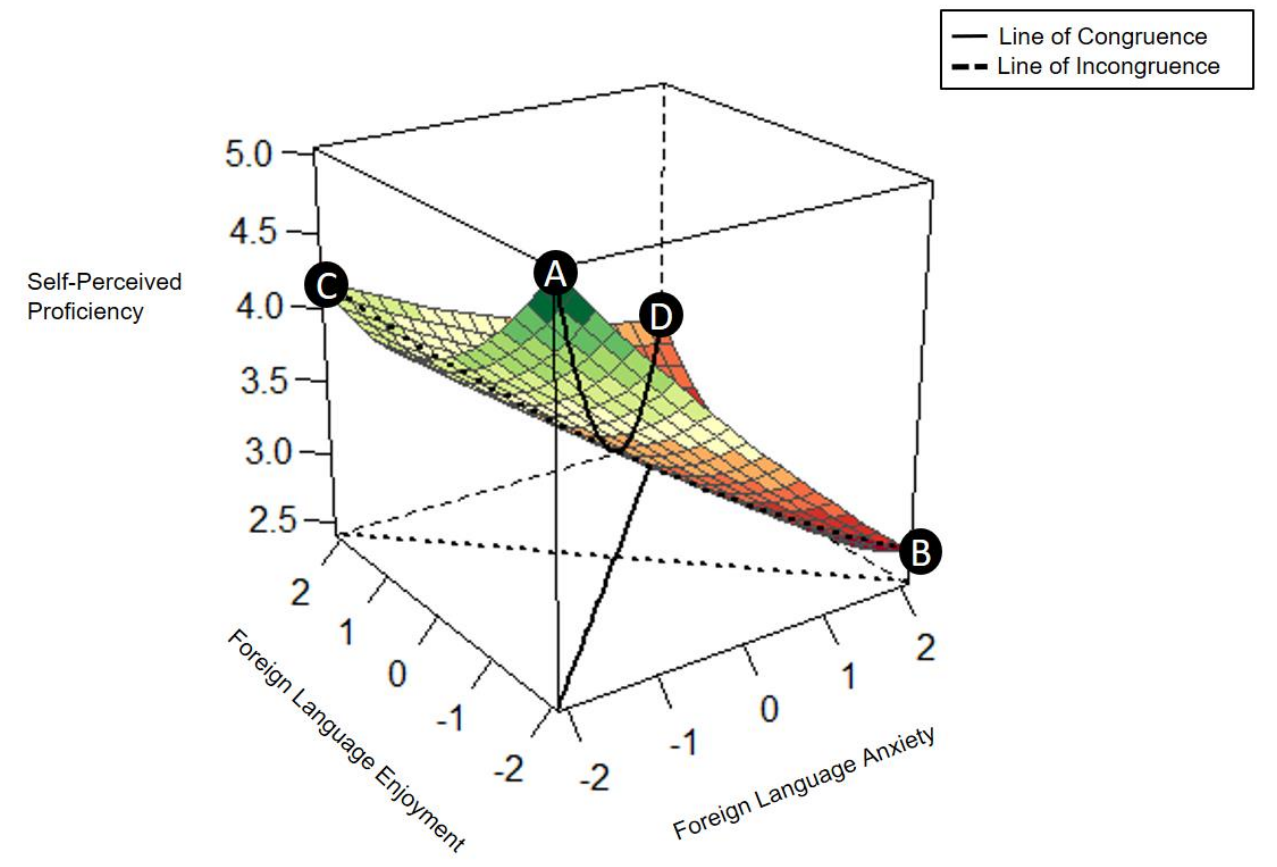

Figure 2. Response surface model of SPP (first angle).

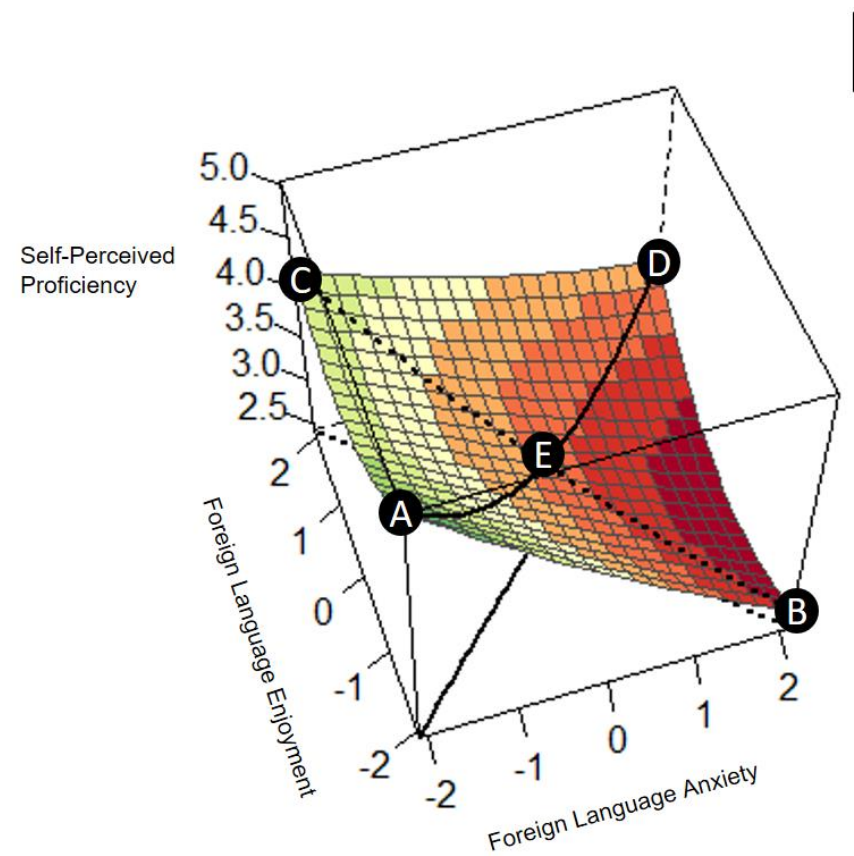

Figure 3. Response surface model of SPP (second angle). 


\section{DISCUSSION}

The aims of this study were to examine an existing dataset through the lens of polynomial regression with response surface analysis and, thereby, to reveal the complexity of the interaction between FLCA and FLE and its subsequent effect on SPP. This study provides the first example of the use of polynomial regression with response surface analysis in examining individual differences in applied linguistics.

As the core result of this study, a statistically significant polynomial regression model between FLCA and FLE as independent variables and SPP as dependent variable was reported. A significant slope was found on the line of incongruence, where FLCA and FLE were experienced at opposite levels (e.g. high FLCA and low FLE). The curvature of the line of incongruence was insignificant. Therefore, as the FLCA of the FL learner decreased and the FLE increased, a linear increase in SPP was predicted. The results of this line of incongruence clearly replicated findings of previous studies utilising correlational and linear methods, namely that FLCA was a hindrance to SPP and FLE was a facilitating factor (Li et al., 2019; Teimouri et al., 2019). However, this simplistic interpretation of the interaction between FLCA and FLE is only applicable to FL learners whose positive and negative emotions are at opposite ends, such as a level of FLE and a low level of FLCA. As FL learners' emotions come in all shapes and sizes, it is also necessary to understand the interaction between FLCA and FLE when each emotion is experienced with equal intensity (e.g. equally low FLCA and FLE).

In fact, the added value of using polynomial regression with response surface analysis is revealed in the results garnered from the line of congruence - where FLCA and FLE were experienced at equal levels. Methodologically speaking, a statistically significant slope and curvature were found for the line of congruence. The negative slope indicated that as FLCA and 
FLE increased, a decreased in SPP was visible. However, this decrease did not occur linearly and rather took a convex shape where equally low levels of FLCA and FLE resulted in the highest level of SPP. This specific finding of high SPP as the result of low FLCA and low FLE ought to be emphasised. Previous linear studies, including our own, have found an individual negative relationship between FLCA and real or perceived proficiency (Botes et al., 2020b; Teimouri et al., 2019), as well as an individual positive relationship between FLE and real or perceived proficiency (Botes et al, 2020a; Li et al., 2019). Yet, in the instance where the FL learner experienced low FLCA and low FLE a resultant high SPP was observed. This high SPP can probably be attributed to a lack of anxiety in the FL learner, however the lack of enjoyment seemed to have no discernible negative impact. This lack of anxiety seems to compensate for the lack of enjoyment in the FL learner and still result in a high SPP. This compensatory effect is visible further along the line of congruence as well, where a high FLE (and equally high FLCA) resulted in a moderate SPP. Thus, the positive impact of a high level of FLE compensated for negative impact of the high level of FLCA experienced by the FL learner to yield a positive outcome of an overall moderate SPP. This intricate pattern of compensatory effects could not have been gained through linear methods and practically demonstrates the use of polynomial regression with response surface analysis in examining individual differences data.

It should also be noted that the line of congruence provides additional insight into the individual sway both FLCA and FLE hold in the interaction effect. The level of SPP was considerably greater as a result of extremely low FLCA and FLE, as opposed to the moderate SPP garnered from an extremely high FLCA and FLE. Therefore, in the interaction between FLCA and FLE and its resultant effect on SPP, a lower level of FLCA will be more beneficial to creating a greater SPP in the FL learner than a higher level of FLE. This greater impact of FLCA on SPP in 
comparison to FLE in the interaction effect has some basis in the literature. Research on the impact of positive and negative emotions have indicated that the impact of negative emotions can at times outweigh the impact of positive emotions in test performance (Chin et al., 2017), achievement motivation (Bartels, 2007), and memory recall (Brainerd et al., 2008). The impact of negative emotions in the FL classroom should therefore not be underestimated, especially as the response surface model shows that even high amounts of positive emotions won't fully compensate for the presence of negative emotions.

The findings of this study have both research and practical implications. The current study provided a demonstration of the use and value that polynomial regression with response surface analysis can offer applied linguistics research. The three-dimensional modelling of an outcome variable as influenced by two independent variables provides a unique opportunity to capture the complexity of a data set. Further endeavours that may benefit from the use of this methodology include examining the interaction between real and perceived proficiency in the target language and an outcome variable such as willingness to communicate, or examining the interaction between willingness to communicate in the FL class of the teacher and the student and an outcome variable such as student proficiency.

The practical implications of the findings of this study specifically concern FL teachers, as the results indicate that high levels of anxiety in the FL classroom cannot be fully offset by high levels of enjoyment. Therefore, FL teachers need to prioritize the lowering of FLCA in their classrooms. Fully eliminating FLCA from the FL classroom would practically be nearly impossible; however, the FL teacher should attempt to create a positive classroom environment where students are allowed to make errors without fearing harsh words or ridicule. Teachers can also empathize with students and train them to handle their FLCA in a constructive manner. This 
may include less prescriptive approaches with a strong focus on grammar and pronunciation, which have been found to contribute to the level of anxiety in FL learners (Young, 1991) or by implementing learning strategies such as self-driven learning (Dupuy, 1997), learning through song (Dolean, 2016), and multimedia technologies (Golonka et al., 2014; Oxford, 2017). In addition, Kondo and Ying-Ling (2004) found that emphasising and actively encouraging students to prepare for FL classes, to take time to relax when FL learning, and to practice positive thinking increases students' abilities to cope with language anxiety. Furthermore, the FL teacher can implement other strategies to increase FLE in the classroom, such as interactive games (Allen et al., 2014) and utilising humour and empathetic teaching (Ariza, 2002). Drawing upon Positive Psychology, Oxford (2017) suggested a number of interventions that teachers can use to lower learners' FLCA by boosting their sense of agency, hope, and optimism. In cases in which classroom activity may elicit both anxiety and enjoyment (e.g., public speaking in the target language), FL teachers must keep in mind that, should the FL learners experience both emotions at equally high intensities, the negative effect of FLCA may to some extent 'overpower' any positive effects of FLE.

\section{LIMITATIONS}

The study has several limitations that ought to be considered. Firstly, the sample of FL learners was broad, and no specific target language, country, or age group were investigated. In fact, future response surface models generated from specific target languages or geographical samples may show different slopes and curvatures. Therefore, the extent to which the response surface model generated in this study can be generalised to other contexts is uncertain. Secondly, SPP was measured with a single item. Future studies utilising different measures such as a multiitem scale or a true measure of proficiency might not find the same interaction effect and outcome 
as presented here. Thirdly, the dataset utilised in this study has been used before by the authors (see footnote 1 regarding the previous use of the data; Botes et al., 2020a). Lastly, it should also be noted that using the methodology of polynomial regression and response surface modelling can be a complicated and rather statistical endeavour to undertake. This study attempted to provide a simple overview of the method; however, it did not address the myriad intricacies in the calculation and interpretation of the response surface model that can be found elsewhere (see Edwards, 2009; Humberg et al., 2019; Shanock et al., 2010).

\section{CONCLUSION}

In their study, Dewaele and MacIntyre (2014) likened the established negative emotion variable of FLCA and the emerging positive emotion variable of FLE to the Roman gods Janus, Phobus, and Laetitia. In this study, we re-examined these old gods of the Dewaele and MacIntyre (2014) dataset through the new lens of polynomial regression with response surface analysis. Results indicated that FL students with a lower FLCA and higher FLE had a higher level of SPPechoing the findings of previous studies that used linear and correlational methods (Dewaele \& MacIntyre, 2014). However, FL learners who experienced FLCA and FLE at equal intensities yielded a complex pattern of SPP, where the presence of one emotion at times compensated for the lack of another. In addition, the greater impact of anxiety in determining the perceived proficiency of the FL learner was observed. Although tried-and-tested methods of correlational and linear hypotheses regarding positive and negative emotions are not without value, polynomial regression and response surface analysis can reflect complexities in FL emotion data on a more fine-grained level. 


\section{REFERENCES}

Allen, L. K., Crossley, S. A., Snow, E. L., \& McNamara, D. S. (2014). L2 writing practice: Game enjoyment as a key to engagement. Language Learning \& Technology, 18(2), 124150.

Ariza, E. N. (2002). Resurrecting “old” language learning methods to reduce anxiety for new language learners: Community language learning to the rescue. Bilingual Research Journal, 26(3), 717-728.

Bartels, J. M. (2007). Dispositional positive and negative affect and approach-avoidance achievement motivation. Individual Differences Research, 5(3), 246-259.

Botes, E., Dewaele, J.-M., \& Greiff, S. (2020a). The power to improve: effects of multilingualism and perceived proficiency on enjoyment and anxiety in foreign language learning. European Journal of Applied Linguistics. https://doi.org/10.1515/eujal-20200003

Botes, E., Dewaele, J.-M., \& Greiff, S. (2020b). The foreign language classroom anxiety scale and academic achievement: an overview of the prevailing literature and a metaanalysis. Journal for the Psychology of Language Learning, 2(1), 26-56.

Boudreau, C., MacIntyre, P. D., \& Dewaele, J.-M. (2018). Enjoyment and anxiety in second language communication: An idiodynamic approach. Studies in Second Language Learning and Teaching, 8(1), 149-170. https://doi.org/10.14746/ssllt.2018.8.1.7 
Brainerd, C. J., Stein, L. M., Silveira, R. A., Rohenkohl, G., \& Reyna, V. F. (2008). How does negative emotion cause false memories?. Psychological science, 19(9), 919-925.

Chin, E. C. H., Williams, M. W., Taylor, J. E., \& Harvey, S. T. (2017). The influence of negative affect on test anxiety and academic performance: An examination of the tripartite model of emotions. Learning and Individual Differences, 54, 1-8. https://doi.org/10.1016/j.lindif.2017.01.002

Chopik, W. J., \& Motyl, M. (2016). Ideological fit enhances interpersonal orientations. Social Psychological and Personality Science, 7(8), 759-768. https://doi.org/10.1177/1948550616658096

Cohen, A., Nahum-Shani, I., \& Doveh, E. (2010). Further insight and additional inference methods for polynomial regression applied to the analysis of congruence. Multivariate Behavioral Research, 45(5), 828-852. https://doi.org/10.1080/00273171.2010.519272

De Ruiter, N. M. P., Shirvan, M. E., \& Talebzadeh, N. (2019). Emotional processes of ForeignLanguage learning situated in real-time teacher support: Ecological psychology. Ecological Psychology, 31(2), 127-145. https://doi.org/10.1080/10407413.2018.1554368

Dewaele, J.-M. (2010). Multilingualism and affordances: Variation in self-perceived communicative competence and communicative anxiety in French L1, L2, L3 and L4. International Review of Applied Linguistics in Language Teaching, 48(2-3), 105-129. https://doi.org/10.1515/iral.2010.006 
Dewaele, J.-M., \& Alfawzan, M. (2018). Does the effect of enjoyment outweigh that of anxiety in foreign language performance? Studies in Second Language Learning and Teaching, 8(1), 21-45. https://doi.org/10.14746/ss1lt.2018.8.1.2

Dewaele, J.-M., Chen, X., Padilla, A. M., \& Lake, J. (2019). The flowering of positive psychology in foreign/second language teaching and acquisition research. Frontiers in Psychology, 10, 2128.

Dewaele, J.-M., \& Dewaele, L. (2017). The dynamic interactions in foreign language classroom anxiety and foreign language enjoyment of pupils aged 12 to 18. A pseudo-longitudinal investigation. Journal of the European Second Language Association, 1(1), 12-22. https://doi.org/10.22599/jesla.6

Dewaele, J.-M., \& Proietti Ergün, A. L. (2020). How different are the relations between enjoyment, anxiety, attitudes/motivation and course marks in pupils' Italian and English as foreign languages? Journal of the European Second Language Association, 4(1), 4557. http://doi.org/10.22599/jesla.65

Dewaele, J.-M., \& Ip, T. S. (2013). The link between Foreign Language Classroom Anxiety,Second Language Tolerance of Ambiguity and Self-rated English proficiency among Chinese learners. Studies in Second Language Learning and Teaching, 3(1), 4766.

Dewaele, J.-M., \& MacIntyre, P. D. (2014). The two faces of Janus? Anxiety and enjoyment in the foreign language classroom. Studies in Second Language Learning and Teaching, $4(2), 237-274$. 
Dewaele, J.-M., \& MacIntyre, P. D. (2016). Foreign language enjoyment and foreign language classroom anxiety. The right and left feet of FL learning? In P. D. MacIntyre, T. Gregersen, \& S. Mercer (Eds.), Positive Psychology in SLA (pp. 215-236). Bristol, UK: Multilingual Matters.

Dewaele, J.-M., MacIntyre, P. D., Boudreau, C., \& Dewaele, L. (2016). Do girls have all the fun? Anxiety and enjoyment in the foreign language classroom. Theory and practice of second language acquisition, 2(1), 41-63.

Dewaele, J.-M., Özdemir, C., Karci, D., Uysal, S., Özdemir, E. D., \& Balta, N. (2019). How distinctive is the foreign language enjoyment and foreign language classroom anxiety of Kazakh learners of Turkish? Applied Linguistics Review. https://doi.org/10.1515/applirev-2019-0021

Dolean, D. D. (2016). The effects of teaching songs during foreign language classes on students' foreign language anxiety. Language Teaching Research, 20(5), 638-653. https://doi.org/10.1177/1362168815606151

Dörendahl, J., Niepel, C., \& Greiff, S. (2020). Actually getting some satisfaction on the job: need-supply fit of fundamental motives at work. Frontiers in Psychology, 11, 1740.

Dupuy, B. C. (1997). Literature circles: An alternative framework for increasing intermediate FL students' comprehension and enjoyment of texts in the target language. Mosaic: A Journal for Language Teachers, 5(1), 13-16. 
Edwards, J. R. (1994). The Study of Congruence in Organizational Behavior Research: Critique and a Proposed Alternative. Organizational Behavior and Human Decision Processes, 58(1), 51-100. https://doi.org/10.1006/obhd.1994.1029

Edwards, J. R. (2002). Alternatives to difference scores: Polynomial regression analysis and response surface methodology. In F. Drasgow \& N. Schmitt (Eds.), Measuring and analyzing behavior in organizations: Advances in measurement and data analysis (pp. 350-400). San-Francisco, CA: Jossey-Bass.

Edwards, J. R. (2007). Polynomial Regression and Response Surface Methodology. In C. Ostroff \& T. A. Judge (Eds.), Perspectives on Organisational Fit (pp. 361-372). San-Francisco, CA: Jossey-Bass.

Edwards, J. R. (2009). Latent Variable Modeling in Congruence Research: Current Problems and Future Directions. Organizational Research Methods, 12(1), 34-62. https://doi.org/10.1177/1094428107308920

Edwards, J. R., \& Cable, D. M. (2009). The value of value congruence. Journal of Applied Psychology, 94(3), 654-677. https://doi.org/10.1037/a0014891

Edwards, J. R., \& Parry, M. E. (1993). On the Use of Polynomial Regression Equations As An Alternative to Difference Scores in Organizational Research. Academy of Management Journal, 36(6), 1577-1613. https://doi.org/10.5465/256822

Fairclough, S. H., Tattersall, A. J., \& Houston, K. (2006). Anxiety and performance in the British driving test. Transportation Research Part F: Traffic Psychology and Behaviour, 9(1), 43-52. 
Fredrickson, B. (2001). The role of positive emotions in positive psychology: The broaden-andbuild theory of positive emotions. American Psychologist, 56(3), 218-226.

Ghorbandordinejad, F., \& Ahmadabad, R. M. (2016). Examination of the Relationship Between Autonomy and English Achievement as Mediated by Foreign Language Classroom Anxiety. Journal of Psycholinguistic Research, 45(3), 739-752. https://doi.org/10.1007/s10936-015-9371-5

Gkonou, C. (2017). Towards an Ecological Understanding of Language Anxiety. In C. Gkonou, M. Daubney, \& J.-M. Dewaele (Eds.), New Insights into Language Anxiety (pp. 136156). Bristol, UK: Multilingual Matters.

Golonka, E. M., Bowles, A. R., Frank, V. M., Richardson, D. L., \& Freynik, S. (2014). Technologies for foreign language learning: a review of technology types and their effectiveness. Computer assisted language learning, 27(1), 70-105.

Horwitz, E. K. (2010). Foreign and second language anxiety. Language Teaching, 43(2), 154167. https://doi.org/10.1017/S026144480999036X

Horwitz, E. K., Horwitz, M. B., \& Cope, J. (1986). Foreign Language Classroom Anxiety. The Modern Language Journal, 70(2), 125-132. https://doi.org/10.1111/j.15404781.1986.tb05256.x

Humberg, S., Nestler, S., \& Back, M. D. (2019). Response surface analysis in personality and social psychology: Checklist and clarifications for the case of congruence hypotheses. Social Psychological and Personality Science, 10(3), 409-419. https://doi.org/10.1177/1948550618757600 
Ilmarinen, V.-J., Lönnqvist, J.-E., \& Paunonen, S. (2016). Similarity-attraction effects in friendship formation: Honest platoon-mates prefer each other but dishonest do not. Personality and Individual Differences, 92, 153-158. https://doi.org/10.1016/j.paid.2015.12.040

Jameson, M. M. (2014). Contextual factors related to math anxiety in second-grade children. The Journal of Experimental Education, 82(4), 518-536.

Jiang, Y., \& Dewaele, J.-M. (2019). How unique is the foreign language classroom enjoyment and anxiety of Chinese EFL learners? System, 82, 13-25. https://doi.org/10.1016/j.system.2019.02.017

Khajavy, G. H., MacIntyre, P. D., \& Barabadi, E. (2018). Role of the emotions and classroom environment in Willingness to Communicate. Studies in Second Language Acquisition, 40(3), 605-624. https://doi.org/10.1017/S0272263117000304

Kondo, D. S., \& Ying-Ling, Y. (2004). Strategies for coping with language anxiety: The case of students of English in Japan. ELT Journal, 58(3), 258-265.

Li, C., Dewaele, J.-M., \& Jiang, G. (2019). The complex relationship between classroom emotions and EFL achievement in China. Applied Linguistics Review. https://doi.org/10.1515/applirev-2018-0043

Li, C., Jiang, G., \& Dewaele, J.-M. (2018). Understanding Chinese high school students' Foreign Language Enjoyment: Validation of the Chinese version of the Foreign Language Enjoyment scale. System, 76, 183-196. https://doi.org/10.1016/j.system.2018.06.004 
Lu, Z., \& Liu, M. (2011). Foreign language anxiety and strategy use: A study with Chinese undergraduate EFL learners. Journal of Language Teaching and Research, 2(6), 1298.

MacIntyre, P. D. (1995). How does anxiety affect second language learning? A reply to Sparks and Ganschow. The Modern Language Journal, 79(1), 90-99. https://doi.org/10.1111/j.1540-4781.1995.tb05418.x

MacIntyre, P. D. (2017). An overview of language anxiety research and trends in its development. In C. Gkonou, M. Daubney, \& J.-M. Dewaele (Eds.), New Insights into Language Anxiety: Theory, Research and Educational Implications, (pp. 11-30). Bristol, UK: Multilingual Matters.

MacIntyre, P. D., Gregersen, T., \& Mercer, S. (2019). Setting an agenda for Positive Psychology in SLA: Theory, practice, and research. The Modern Language Journal, 103(1), 262-274. https://doi.org/10.1111/modl.12544

Mierzwa, E. (2018). The relationship between Foreign Language Enjoyment and gender among secondary grammar school students. The Journal of Education, Culture, and Society, 1(2), 117-135.

Milatz, A., Lüftenegger, M., \& Schober, B. (2015). Teachers' relationship closeness with students as a resource for teacher wellbeing: A response surface analytical approach. Frontiers in Psychology, 6. https://doi.org/10.3389/fpsyg.2015.01949

Mughal, S., Walsh, J., \& Wilding, J. (1996). Stress and work performance: The role of trait anxiety. Personality and Individual differences, 20(6), 685-691. 
Oxford, R. (2017). Teaching and researching language learning strategies: Self-regulation in context. New York: Routledge.

Saito, Y., \& Samimy, K. K. (1996). Foreign language anxiety and language performance: A study of learner anxiety in beginning, intermediate, and advanced-level college students of Japanese. Foreign Language Annals, 29(2), 239-249.

Schönbrodt, F. D., \& Humberg, S. (2018). RSA: An R package for response surface analysis (version 0.9.12) [Computer software]. https://cran.r-project.org/package=RSA

Seligman, M. E. P., \& Csikszentmihalyi, M. (2014). Positive Psychology: An introduction. In M. Csikszentmihalyi (Ed.), Flow and the Foundations of Positive Psychology: The Collected Works of Mihaly Csikszentmihalyi (pp. 279-298). Amsterdam, Netherlands: Springer. https://doi.org/10.1007/978-94-017-9088-8_18

Shanock, L. R., Baran, B. E., Gentry, W. A., Pattison, S. C., \& Heggestad, E. D. (2010). Polynomial regression with response surface analysis: A powerful approach for examining moderation and overcoming limitations of difference scores. Journal of Business and Psychology, 25(4), 543-554. https://doi.org/10.1007/s10869-010-9183-4

Shirvan, M. E., \& Talebzadeh, N. (2018). Exploring the fluctuations of Foreign Language Enjoyment in conversation: An idiodynamic perspective. Journal of Intercultural Communication Research, 47(1), 21-37. https://doi.org/10.1080/17475759.2017.1400458

Spahn, C., Echternach, M., Zander, M. F., Voltmer, E., \& Richter, B. (2010). Music performance anxiety in opera singers. Logopedics Phoniatrics Vocology, 35(4), 175-182. 
Teimouri, Y., Goetze, J., \& Plonsky, L. (2019). Second language anxiety and achievement: A meta-analysis. Studies in Second Language Acquisition, 1-25. https://doi.org/10.1017/S0272263118000311

Thompson, A. S., \& Khawaja, A. J. (2016). Foreign language anxiety in Turkey: The role of multilingualism. Journal of Multilingual and Multicultural Development, 37(2), 115-130.

Wei, H., Gao, K., \& Wang, W. (2019). Understanding the Relationship Between Grit and Foreign Language Performance Among Middle School Students: The Roles of Foreign Language Enjoyment and Classroom Environment. Frontiers in Psychology, 10. https://doi.org/10.3389/fpsyg.2019.01508

Young, D. J. (1991). Creating a low-anxiety classroom environment: What does language anxiety research suggest?. The Modern Language Journal, 75(4), 426-439.

Zhang, H., Dai, Y., \& Wang, Y. (2020). Motivation and second foreign language proficiency: The mediating role of Foreign Language Enjoyment. Sustainability, 12(4), 1302. https://doi.org/10.3390/su12041302 